\title{
Using the relationship between eye diameter and body length to detect the effects of long-term starvation on Antarctic krill Euphausia superba
}

\author{
Hyoung-Chul Shin ${ }^{1, *}$, Stephen Nicol $^{2}$ \\ ${ }^{1}$ Institute of Antarctic and Southern Ocean Studies, University of Tasmania, Hobart, GPO Box 252-77, Tasmania 7001, Australia \\ ${ }^{2}$ Antarctic Marine Living Resources Program, Australian Antarctic Division, Channel Highway, Kingston, Tasmania 7050, \\ Australia
}

\begin{abstract}
Body shrinkage may be one of the strategies that Antarctic krill use to cope with food scarcity, particularly during winter. Despite their demonstrated ability to shrink, there are only very limited data to determine how commonly shrinkage occurs in the wild. It has been previously shown that laboratory-shrunk krill tend to conserve the size of the eye. This study examined whether the relationship between the eye diameter and body length could be used to detect whether krill had been shrinking. By tracking individuals over time and examining specimens sampled as groups, it was demonstrated that fed and starved krill are distinguishable by the relationship between the eye diameter and body length. The eye diameter of starved krill did not decrease, even when the animals had shrunk in overall body length. The eye diameter of well-fed krill continued to increase as overall length increased. This created a distinction between fed and starved krill, while no separation was detected in terms of the body length to weight relationship. Eye growth of krill re-commenced with re-growth of krill following shrinkage although there was some time lag. It would take approximately 2 moult cycles of shrinkage at modest rates to significantly change the eye diameter to body length relationship between normal and shrunk krill. If krill starve for a prolonged period in the wild, and hence shrink, the eye diameter to body length relationship should be able to indicate this. This would be particularly noticeable at the end of winter.
\end{abstract}

KEY WORDS: Antarctic krill $\cdot$ Shrinkage $\cdot$ Starvation $\cdot$ Winter $\cdot$ Eye Resale or republication not permitted without written consent of the publisher

\section{INTRODUCTION}

Antarctic krill Euphausia superba (hereafter 'krill') has been shown, both from laboratory experiments and field studies, to be able to undergo negative growth under starvation or severe food limitation (Ikeda \& Dixon 1982, Quetin \& Ross 1991, Nicol et al. 1992). Shrinkage is one of the strategies that krill may use to cope with food scarcity, particularly during

*Present address: Polar Sciences Laboratory, Korea Ocean Research and Development Institute, Ansan, PO Box 29, Seoul 425-600, Republic of Korea. E-mail: hcshin@kordi.re.kr winter, but there are only very limited data to determine how commonly shrinkage occurs in the wild. Despite the mounting evidence of shrinkage occurring in a variety of species of krill, it is still not a generally accepted phenomenon and is often viewed as merely a laboratory artifact (Nicol 2000). Body shrinkage can interfere with the relationship between body length and age, and thus affect length frequency analyses traditionally used in population dynamics (Ettershank 1984). As there are currently no reliable independent measures of age in krill (Nicol 2000), this can introduce significant uncertainty. Shrinkage has been reported in a number of other euphausiid species (Dalpadado \& Ikeda 1989, Hosie \& Ritz 1989, Marinovic \& Mangel 
1999). However, because of the longer life span and extended food-limited periods, shrinkage is more likely to pose a problem in studies of Antarctic krill than for other euphausiids.

The controversies surrounding winter growth and shrinkage of krill have not been resolved (Nicol 2000). The only available year-round length frequency data have been interpreted in different ways (Stepnik 1982, McClatchie 1988, McClatchie et al. 1991) and the scarce direct field observations of winter growth do not agree, illustrating both shrinkage and apparent growth (Quetin \& Ross 1991, Huntley et al. 1994). Krill have been observed adopting a range of behaviors in winter including shrinkage (Quetin \& Ross 1991), carnivorous feeding (Huntley et al. 1994), under-ice feeding (Stretch et al. 1988) as well as epibenthic swarming (Gutt \& Siegel 1994). They are also known to overwinter in ice-free areas as shown by winter fishing activities around South Georgia (Everson \& Goss 1991). Therefore, krill are not dependent on a single strategy to survive the period of greatest food limitation. Nevertheless, population processes during winter, when shrinkage might occur, are thought to be critical in determining the krill populations' success in the following season (Smetacek et al. 1990). The extent and duration of sea ice cover during winter has been proposed as a major factor governing such processes, largely through the mediation of sea-ice biota, which have been suggested as a major food source for krill larvae and adults (Siegel \& Loeb 1995, Loeb et al. 1997). Because there remains uncertainty regarding whether krill are growing, shrinking or remaining the same size over winter, or whether there are regional differences in winter growth and food utilization, there is a need to develop techniques to determine the growth history of individuals and populations during winter.

It has been suggested that the relationship between the body length and the number of crystalline cones in the krill eye or the eye diameter might indicate whether the krill had experienced shrinkage (Sun et al. 1995, Sun 1997). The authors indicated that when krill shrink in length, the number of crystalline cones in the compound eye and the eye diameter appear to remain constant. In essence, shrunk krill should have more cones in their eyes, and thus should have larger eyes, for a given body length than krill which have not shrunk. It remains to be determined, however, under what conditions the eye diameter to body length relationship would become differentiable between fed animals and starved ones; how much shrinkage is needed, and for how long such shrinkage needs to be maintained. Sun et al. (1995) also questioned if the eye would start to grow immediately once the body growth re-commenced following a period of shrinkage or whether eye growth would begin only after the origi- nal body length had been regained. This has significant implications for the potential use of the eye size as an indicator of shrinkage. Sun (1997) later suggested that the eye diameter would remain constant while the rest of the body was recovering to the original size after shrinkage. Then the modified eye diameter to body length relationship would be lost. If, on the other hand, eye growth re-commences with body growth, this modified relationship would be preserved.

This study aimed to examine, from direct observation of individuals over time and from inspection of animals sampled as groups, whether the eye diameter of krill is unaffected by starvation and consequent body shrinkage. It was also designed to determine if resumed food supply following starvation re-initiates growth both in body length and in eye diameter. It further attempted to assess what conditions are required for an appreciable difference to be generated in the eye diameter to body length relationship between normal and shrunk krill.

\section{MATERIALS AND METHODS}

Experimental krill. A large number of juvenile Antarctic krill were collected on 15 April 1997 at $64^{\circ} 19^{\prime} \mathrm{S}, 110^{\circ} 57^{\prime} \mathrm{E}$, just north of the ice edge in East Antarctica with an RMT1+8. The krill were kept in a cold room on board while being transported to the home aquarium. Then they were maintained in the dark at $2 \pm 0.5^{\circ} \mathrm{C}$ under low concentrations of diatoms until the experiment started at the beginning of August 1997. A mixture of 3 cultured algal species, Phaeodactylum tricornutun, Gemingera criophylum and Pyramimonas sp., was given to krill in tanks approximately once per week. For 1 wk before the start of the experiment, no new algal food was given.

Organization of the experiment. The experimental krill were selected to cover a narrow size range (approximately $7.5 \mathrm{~mm}$ in carapace length, around $24 \mathrm{~mm}$ in total length) and were kept individually in 21 plastic jars at $0^{\circ} \mathrm{C}$ in the dark. An initial group of 25 krill was removed at the start of the experiment.

Phase 1: One group was fed Phaeodactylum tricornutum at $5 \times 10^{5}$ cells ml ${ }^{-1}$ to attain maximal growth rates (Ikeda \& Thomas 1987) and the other group was placed in filtered seawater. Water exchange and food provision were made every 3 to $4 \mathrm{~d}$. Half of each group, either fed or starved, was assigned to either the Harvest Group or the Monitor Group as they moulted. The krill assigned to the Harvest Group were sacrificed at regular intervals and the animals assigned to the Monitor Group were repeatedly examined as alive. From the Harvest Group, 12 krill were sampled after 5, 10 and 15 wk and then weighed, and the carapace 
length and the eye diameter were measured. For the Monitor Group, the krill at each moult were taken out and weighed, and an image of each krill was taken with an image analysis system. The krill were then replaced in the experimental jars. From the image, the eye diameter (the maximal, vertical dimension of the left eye) and the carapace length (the dorsal distance between the anterior tip of the rostrum and the middorsal posterior edge of the carapace) at each moult were determined. Initially, the aim was to use only unharassed animals from the Harvest Group for the regular sampling. However, at Week 15 , about $1 / 2$ of the krill came from the monitored, and hence disturbed group, due to a dwindling number of animals.

Phase 2: After $15 \mathrm{wk}$, the food regime was reversed; the fed group was starved and the starved group began to receive food. Following the switch, all krill were monitored at each moult, and up to 5 krill were sampled at regular intervals for other experimental purposes. The experiment continued for a further $13 \mathrm{wk}$ following the switch of feeding regimes.
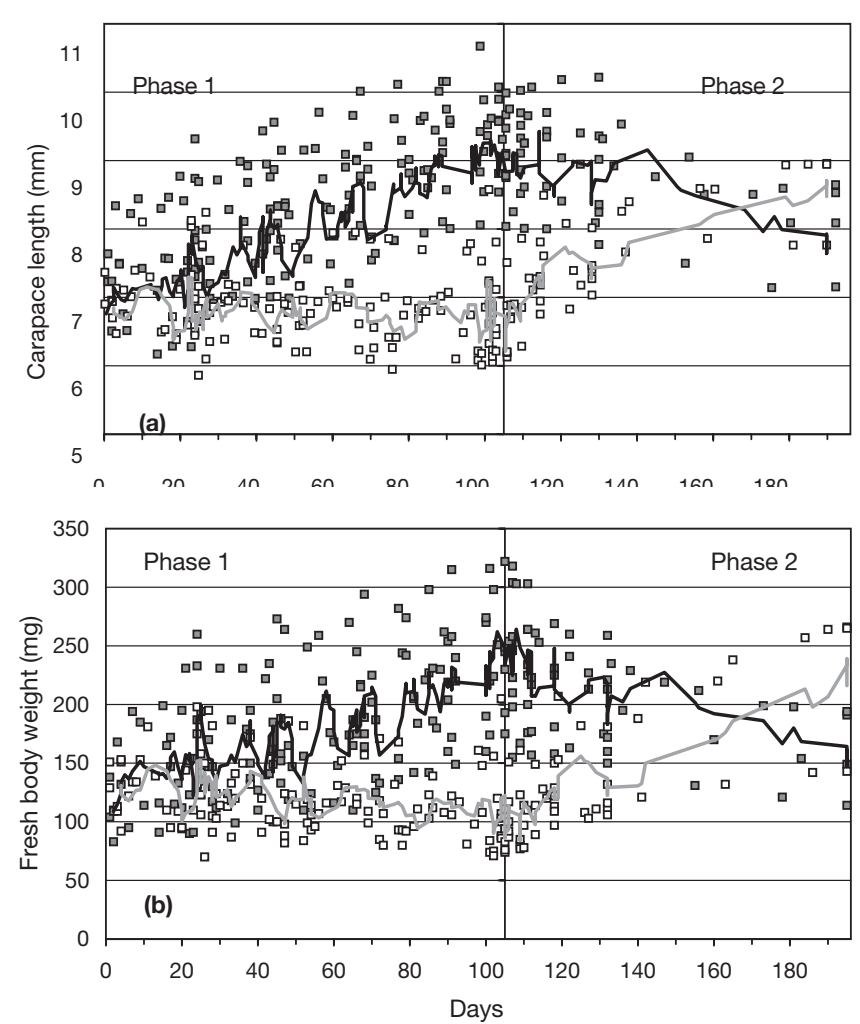

Fig. 1. Change in the body size of the krill from the Monitor Group. (a) Carapace length, (b) fresh body weight. Each data point is a measurement at each moult or at the point of sampling. Day 105 is the point of food regime reversal and hence the point of change from Phase 1 to Phase 2. 'Moving average' lines are drawn from the mean of the last 5 data points. ( $\square$ ) and solid line represent the 'fed and then starved' krill, () and shaded line represent the 'starved and then fed' ones

\section{RESULTS}

\section{Body length to weight relationship and body length to eye diameter relationship}

Throughout the course of the experiment, starved juvenile krill generally shrank in length and lost weight, whereas the well-fed animals grew both in length and weight (Fig. 1). The experimental krill had been on maintenance food levels before the start of the experiment. Thus, the starved krill in Phase 1 did not shrink substantially in length although they lost weight. Fed and starved groups of harvested krill were indistinguishable in terms of the body length to weight relationship, even after $15 \mathrm{wk}$ of extreme treatments (Fig. 2a). The linear regressions of the log-transformed body length versus weight of the fed and starved groups were compared, using a $t$-test (Zar 1996). Equality of the slopes was tested first and a common slope was calculated if the slopes were not significantly different. Then the regressions were tested for
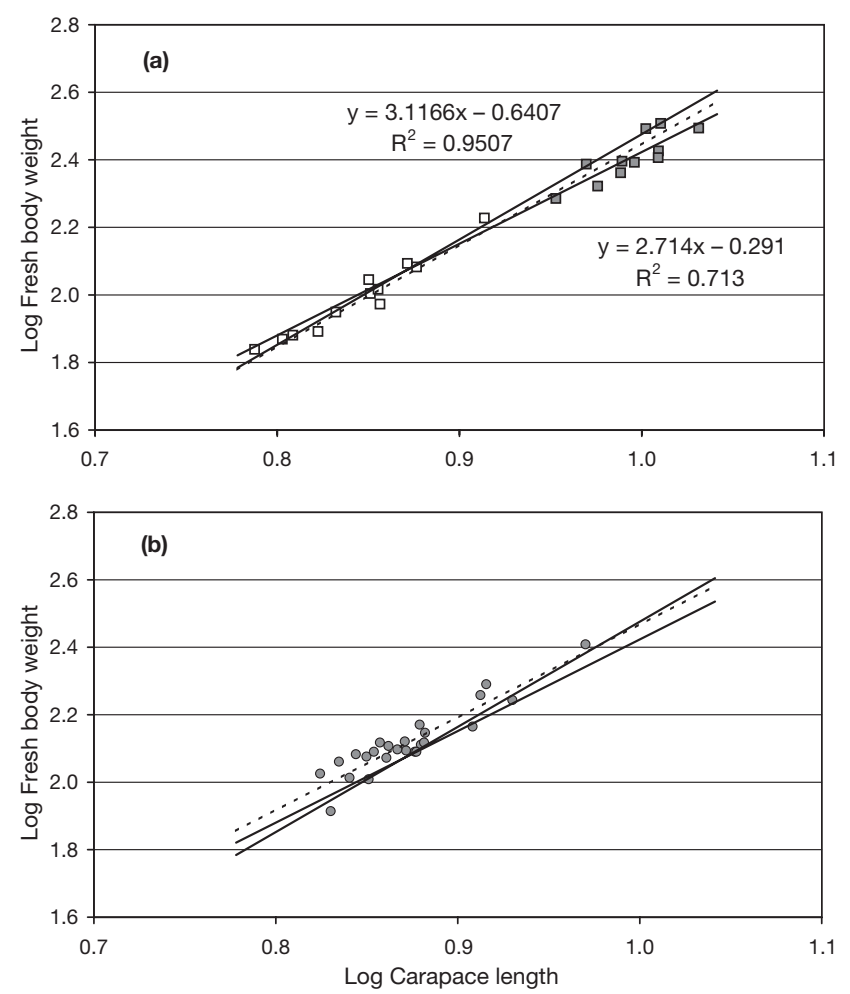

Fig. 2. Relationship between the body length and body weight of well-fed or starved krill. (a) Log[carapace length] versus Log[fresh body weight] of the Harvest Group krill sampled after 15 wk. ( $\square$ ) indicates fed krill and ( $\square$ ) the starved animals. A new regression line (broken) was drawn with the common slope and the common elevation. (b) The length and weight data of the initial group of krill (으), and their regression line (broken) superimposed on the regression lines of the 2 groups of krill fed or starved for $15 \mathrm{wk}$ 
differences in elevation. Neither the slopes nor the elevations of the 2 regression lines from the fed and starved group were significantly different ( $t$-test, $0.2<$ $\mathrm{p}<0.5$ ); sharing a common slope and a common elevation. That is, a single equation could describe the body length to weight relationships of both groups.

In terms of the carapace length to eye diameter relationship, however, the starved krill were separable from the well-fed animals after 15 wk (Fig. 3a). The slopes of the linear relation between the carapace length and eye diameter from the fed krill and the starved ones were not significantly different ( $t$-test, $0.2<\mathrm{p}<0.5$ ), but the elevations were significantly different ( $t$-test, $0.02<\mathrm{p}<0.05$ ); starved krill had larger eyes compared to the fed krill of similar lengths or starved krill were shorter than the fed krill of similar eye diameters.

The body length to weight relationships in krill fed or starved for $15 \mathrm{wk}$ were not only similar but also had not
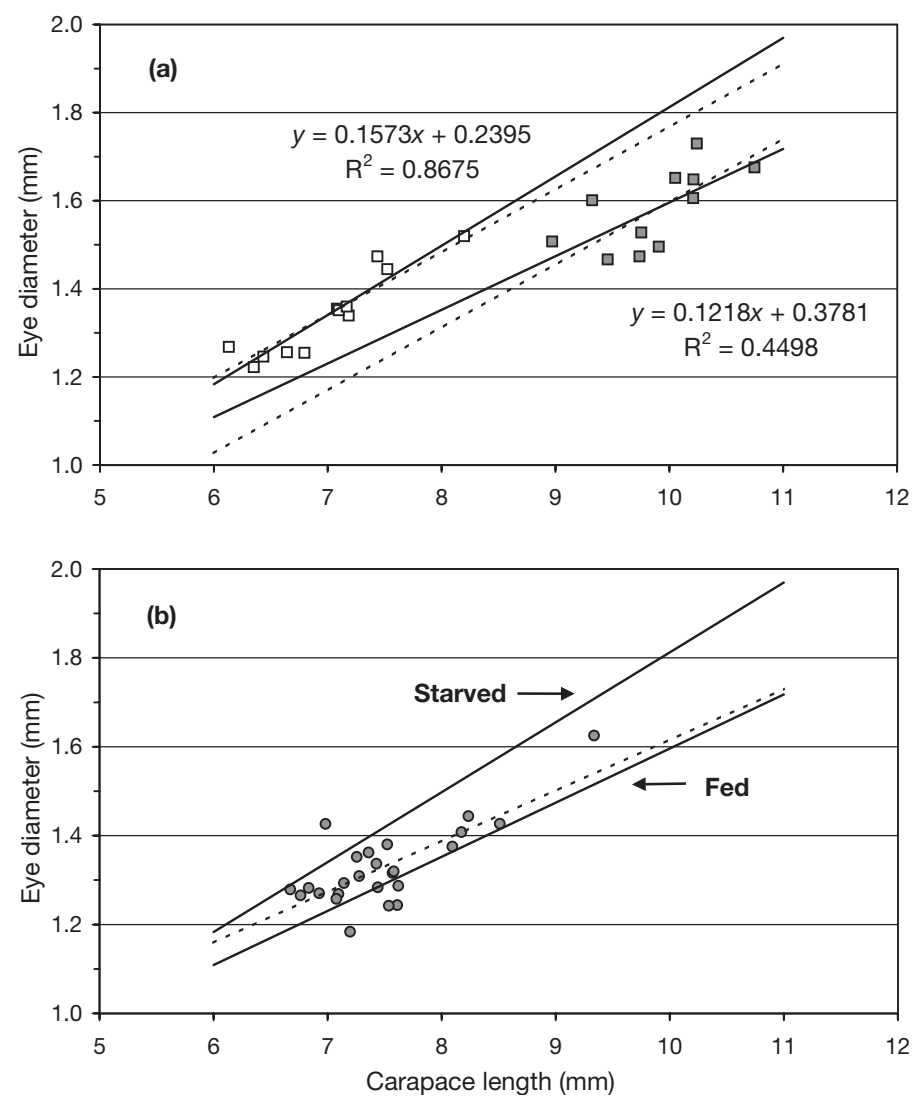

Fig. 3. Relationship between carapace length and eye diameter of the fed or starved krill. (a) The carapace length to eye diameter relationship from the Harvest Group after 15 wk. ( $\square$ ) indicates the fed krill and ( $\square$ ) the starved ones. Broken lines are drawn from the common slope and corrected elevations. (b) The carapace length to eye diameter relationship of the initial group (०), and its regression line (broken) overlaid on the regression lines of the 2 groups of krill fed or starved for $15 \mathrm{wk}$ greatly changed from that of the krill at the start of the experiment. Overall, there was little difference in the length to weight relationship between the initial krill and the krill fed or starved for $15 \mathrm{wk}$ (Fig. 2b). In terms of the body length to eye diameter relationship, however, the initial group was much closer to the fed group than to the starved animals (Fig. 3b). Starved krill were becoming separated from the fed group as shrinkage occurred in the body length but not in the eye diameter.

Because the specimens were selected in a narrow range of body size, the coefficient of determination from the relationships derived tended to be relatively low. However, the separation of fed and starved animals in terms of the carapace length to eye diameter relationship was obvious by Week 15. Such separation appears to have become already manifest $10 \mathrm{wk}$ into the experiment. Two individuals of the $10 \mathrm{wk}$-fed group showed a relationship dissimilar to the rest of the group, being more like starved krill in terms of the carapace length to eye diameter relationship. By removing these 2 data points, a trend could be established for the reduced data set of krill fed or starved for $10 \mathrm{wk}$, similar to that seen in Week 15; there was a common slope but significantly different elevations ( $t$-test, $0.02<\mathrm{p}<0.05)$. A gradual separation of fed and starved krill also took place with time in the Monitor Group (Fig. 4). Despite the small number of specimens, a similar separation was seen to have occurred again $13 \mathrm{wk}$ after the reversal of food regime; the krill starved for $13 \mathrm{wk}$ after a switch from full rations became shorter for a given eye diameter, compared to the krill that were well fed following a long period of starvation (Fig. 4d).

\section{Change in the eye diameter and body length of individually monitored krill}

The eye diameter of the well-fed krill continued to increase as overall length increased. When the previously well-fed krill were starved, eye diameter growth was halted but the diameter of the eye did not decrease. The percentage increment per moult of the eye diameter and of the carapace length are presented from the krill in the Monitor Group, and these demonstrate the overall trend (Fig. 5a,b). These increment rates represent the growth that occurred during 1 moult cycle, i.e. between the previous moult and the current moult. As the measurements had to be made quickly on live animals, a small amount of measurement error was unavoidable, which may account for some of the variation. Nevertheless, a general pattern emerged. During Phase 1 of the experiment, the eye diameter increment per moult of the starved krill approximated zero, whereas at the same time the krill were shrinking marginally in carapace length. When 

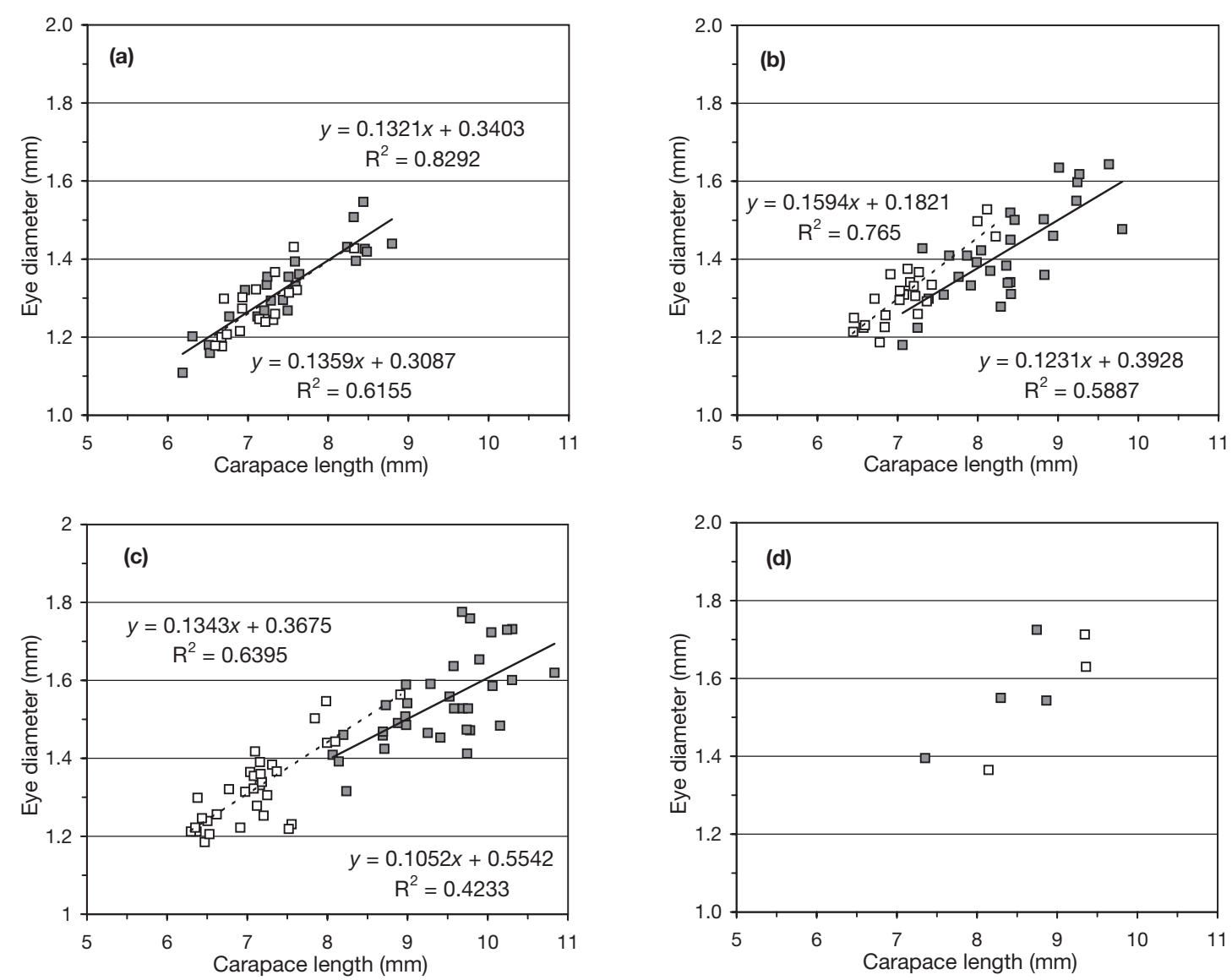

Fig. 4. Carapace length to eye diameter relationship over time from the krill of the Monitor Group. (a) The carapace length to eye diameter relationship during the $1 \mathrm{st} 3 \mathrm{wk}$ of Phase 1, (b) the carapace length to eye diameter relationship during the mid-3 wk of Phase 1, (c) the carapace length to eye diameter relationship during the last 3 wk of Phase 1, (d) the carapace length to eye diameter relationship at the end of Phase 2. (ם) represent the krill fed during Phase 1 and then starved during Phase 2.

(ㅁ) represent the krill starved during Phase 1 and then fed during Phase 2
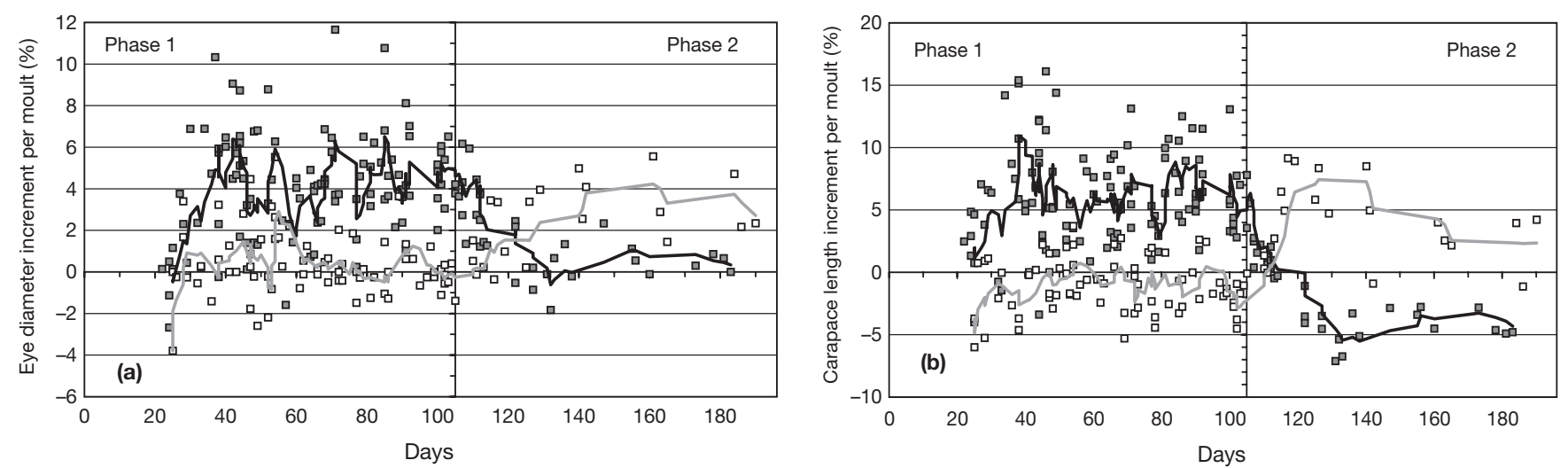

Fig. 5. Eye diameter and carapace length increment in percentage per moult of the individually monitored krill throughout the experiment. (a) Eye diameter growth, (b) carapace length growth. Each data point is a rate of growth that occurred between the day of current moult and the previous moult. Day 105 is the point of food regime reversal and hence the point of change from Phase 1 to Phase 2. 'Moving average' lines are drawn from the average of the last 5 data points. Solid line represents the 'fed and then starved' group, and shaded line the 'starved and then fed' group 
the previously well-fed animals started to starve in Phase 2 and thus shrink, the eye growth fell and settled close to zero. Krill that had been starved responded to food by resuming growth both in body length and eye diameter. The response of the eye diameter to the change in food regimes tended to be slower than that of the carapace length and had some degree of individual variation (Fig. 5a,b). Some krill re-started eye growth after a time lag. Similarly, the eye diameter of
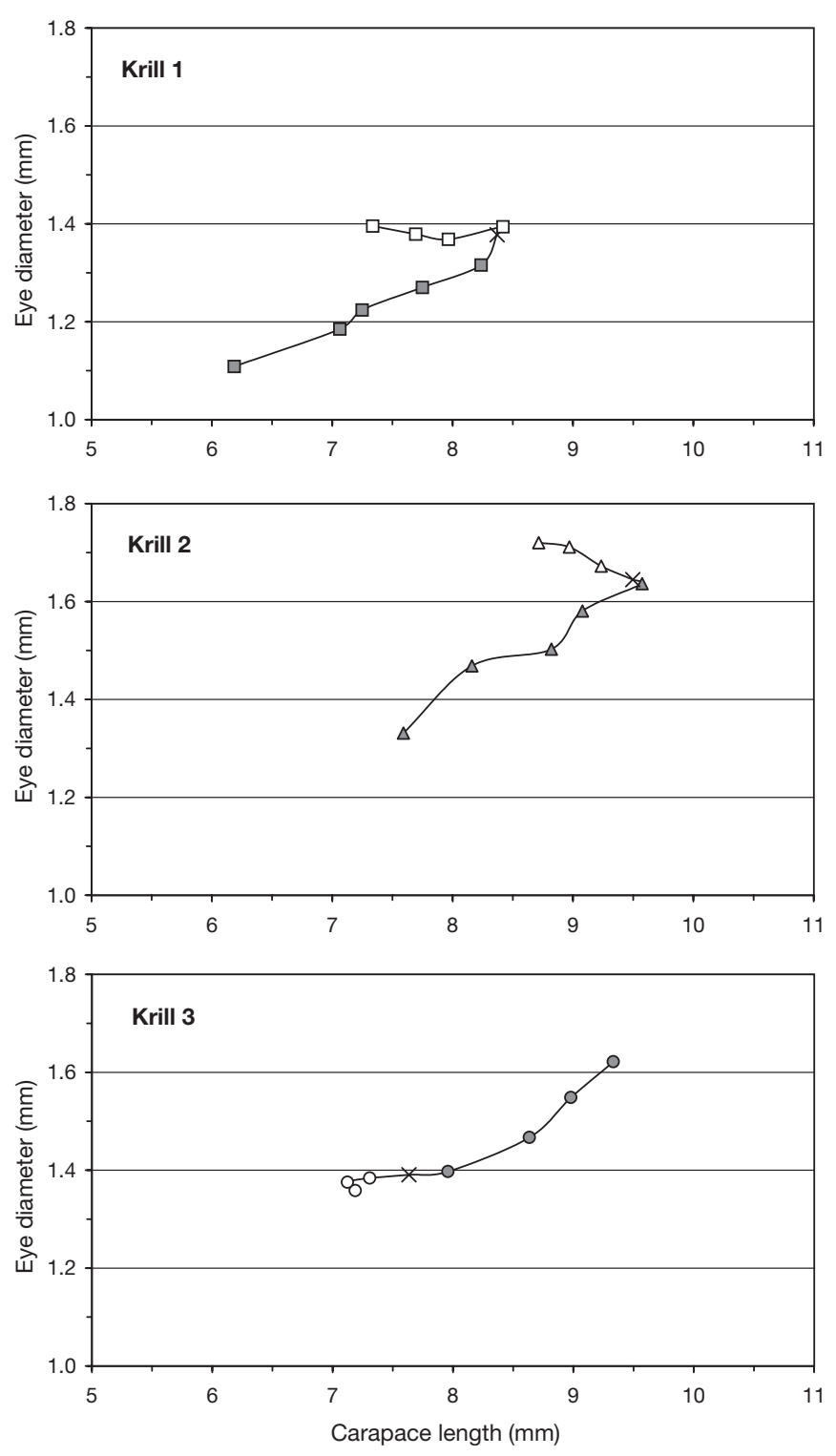

Fig. 6. Trajectories of carapace length and eye diameter of 3 representative krill that completed both the feeding and starvation phase of the experiment. Krill 1 and 2 are from the 'fed and then starved' group and Krill 3 is from the 'starved and then fed' group. Shaded symbols represent feeding krill and open symbols starving ones. The point of food regime reversal is indicated by crosses. Each data point resulted from a moulting event others continued to grow for a short period after body shrinkage commenced. However, these time lags usually lasted only a few weeks, a similar length of time to a single moult cycle. Fig. 6 presents the individual tracks of the eye diameter and carapace length in some krill that were allowed to carry on through the whole period of the experiment. This depicts the varying degree of promptness in the re-initiation or cessation of eye growth between individuals. Krill 1 exhibited a cessation of eye growth almost immediately following the switch to starvation, whereas the eye diameter of Krill 2 continued to grow for almost 2 more moult cycles. Krill 3, which had first been starved and then fed, needed another moult cycle to resume eye growth, while its carapace length started to increase with the switch of the food regime.

\section{DISCUSSION}

This experiment demonstrated, from both tracking individuals over time and examining specimens sampled as groups, that fed and starved krill became distinguishable by the body length to eye diameter relationship. Separation of the fed and starved groups by the body length to eye diameter relationship stems from the response of the eye diameter to the food supply. Eye diameter increases as the krill grow but does not decrease while the overall body length decreases during shrinkage. The body length to weight relationship, which has been regarded as a condition indicator, did not exhibit a difference in the experimental krill, even after $15 \mathrm{wk}$ of extreme treatment. Differences in terms of the body length to weight relationship have already been noted from the field-caught specimens between summer and winter (Siegel 1989, Quetin \& Ross 1991) and also within season (Nicol et al. 2000). Krill in this experiment were juveniles, and it is possible that juvenile krill cannot afford to lose too much body mass while adults have more reserve to dispense with. Therefore, a change in the length to weight relationship may not be as readily apparent in juveniles as in adults. Nevertheless, if krill shrink in length while losing weight, they would have to lose weight more quickly than they decrease in length in order to change the length to weight relationship. In this experiment, when the initially well-fed krill started to lose weight and shrink in response to subsequent starvation, it seems to have occurred in the same way as they had gained weight and had grown in length, but only in reverse. This resulted in krill of the 'fed and then starved' group moving along the same path on the length versus weight plane while growing and then shrinking (Fig. 7). This can be viewed as utilizing the moult cycle to optimize the body length for a given weight. 
While the eye size has the potential to serve as an indicator of shrinkage by staying constant during body shrinkage, it remains to be determined under what circumstances a detectable change might occur. In this experiment, starving krill during Phase 1 shrank at rates between 0 and $2 \%$ moult $^{-1}$. Separation of fed and starved krill in terms of the carapace length to eye diameter relation became evident by Week 15, and this was detectable from around Week 10 excluding a few
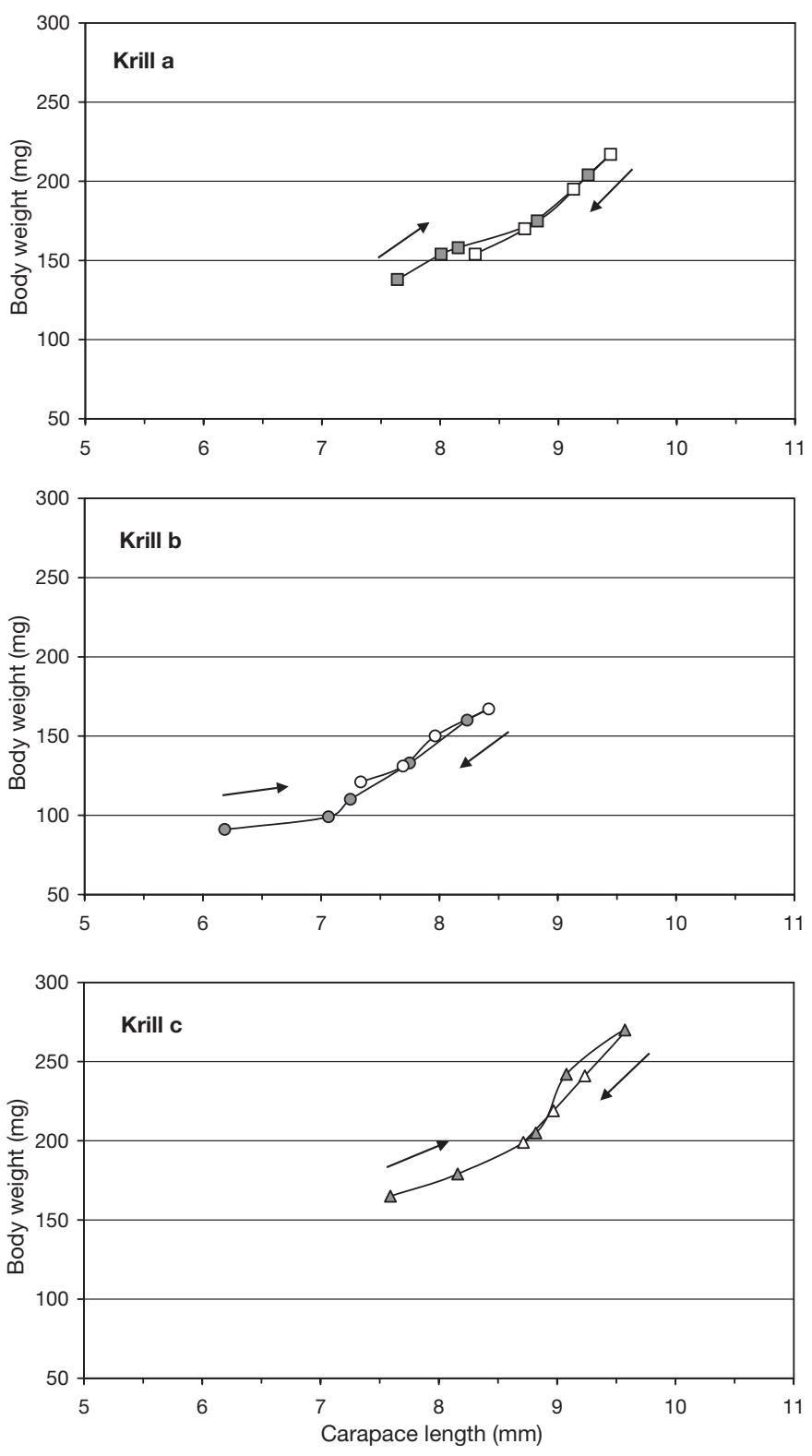

Fig. 7. Trajectories of carapace length and body weight of representative individual krill from the 'fed and then starved' group. Upward arrows indicate the start of the experiment and downward arrows indicate a decline to negative growth caused by starvation. Open symbols represent the starved specimen after the switch to starvation outliers. By Week 10, most of the starved krill had moulted twice and krill that shrank for 2 moults at an average rate more than $1 \%$ moult $^{-1}$ became discernible from the well-fed, normally growing krill, by the body length to eye diameter relationship.

Restoring the food supply after a long period of starvation promoted growth both in carapace length and eye diameter although there was a time lag (Figs. 5 \& 6). Therefore, it appears that krill do not have to regain their original body length before the growth of the eye diameter re-commences. This will make the application of eye size to the population study of krill even more practical because krill will retain the modified body length to eye diameter relationship when they start to grow again.

To illustrate how body shrinkage would affect the body length, the eye diameter and the relationship between the two, a simplified hypothetical growth model was constructed for krill that shrink or do not shrink during winter. The following assumptions were made: (1) krill live for $5 \mathrm{yr}$ and moult 12 times $\mathrm{yr}^{-1}$; (2) krill grow at high rates for the first 4 mo during summer; (3) for the next 3 moults in autumn, krill grow at low rates; (4) during winter krill moult twice and they either stop growing or shrink by $2 \%$ moult $^{-1}$; however, krill in their first winter after hatching, i.e. larvae, do not shrink; and (5) in spring krill start to grow at the same low rates as in autumn and they moult 3 times.

Except for the winter season, growth rates of krill between 1 and $5 \%$ moult $^{-1}$ were assigned to the different seasons each year. The growth rates were set at modest levels within the range of published values. The actual value of growth rates was not deemed significant, as adjusting the growth rates may refine the growth curve but will have no effect on examining the consequences of shrinkage or absence of shrinkage. The function describing the initial relationship between the body length and the eye diameter was modified from Sun (1997), as the current experiment used only juvenile krill in a narrow size range. Sun (1997) obtained the relationship from a wide size range of krill, and described an exponential function between the body length and the eye diameter because it gave a better fit than a linear regression. However, this has not been substantiated and does not appear biologically realistic. A linear relation was established from the combination of body length and eye diameter, which would have fitted Sun's (1997) exponential relationship in the size range he observed. It resulted in a regression line, which had a similar slope to the one from our experiment on juveniles. For krill that do not shrink, the eye diameter of the animal was derived from this relationship throughout. For shrinking krill, the eye diameter was obtained in the same way but was kept constant while the animals were shrinking. 

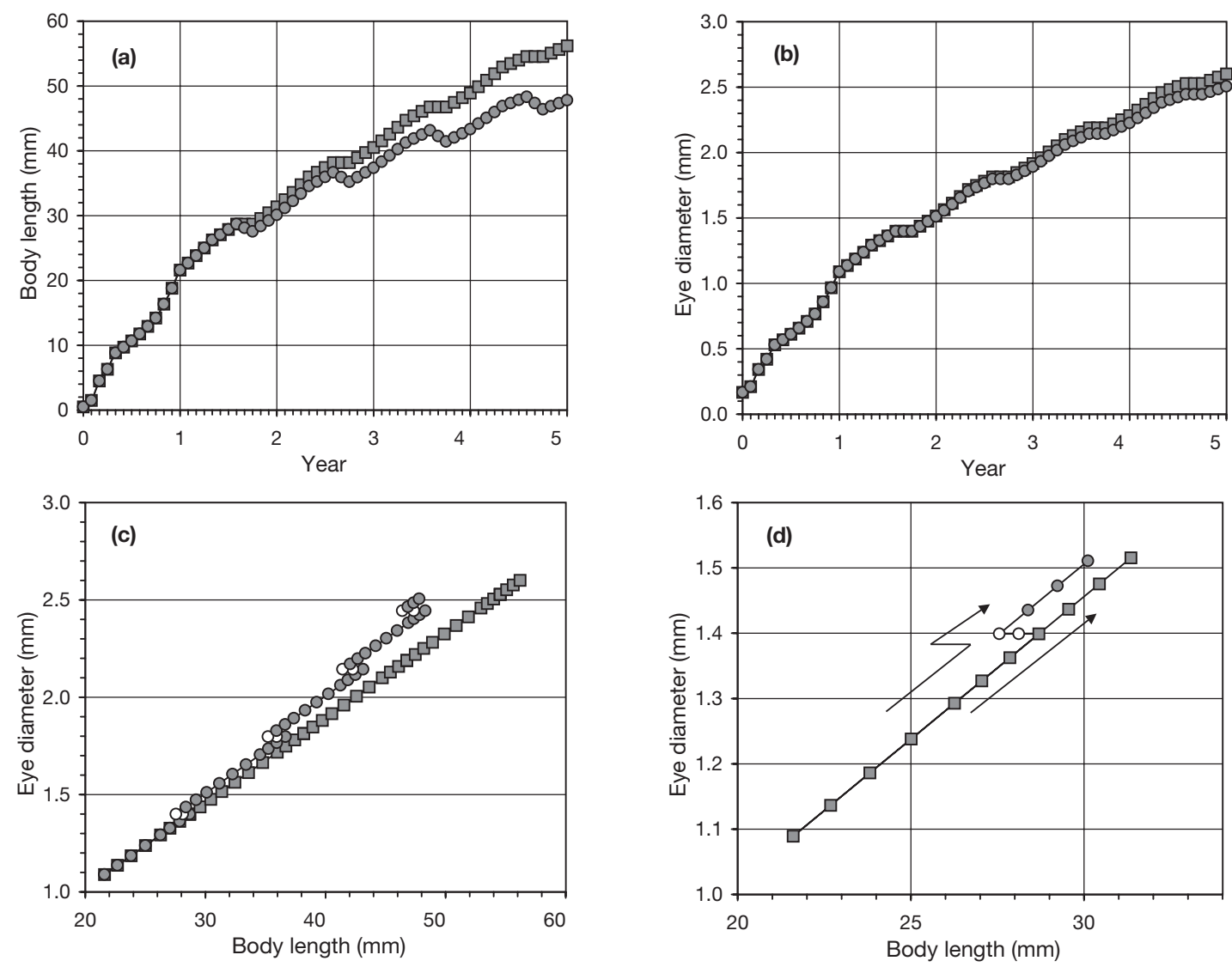

Fig. 8. Hypothetical 5 yr growth of krill that shrink over winter (o) or do not shrink ( $\square$ ). (a) Body length, (b) eye diameter, (c) the relationship between body length and eye diameter, (d) a magnified view of (c), but between the 1st summer and 2nd summer after hatching. Krill shrink in body length only, not in eye diameter. (०) indicate that shrinkage has occurred. Arrows indicate how the body length to eye diameter relationships change sequentially with initial normal growth, shrinkage or zero growth, and then re-growth

When the krill re-commenced growth in spring, the eye diameter also began to grow.

The maximal body length attained by the krill that shrink for 2 moults $\mathrm{yr}^{-1}$ was shorter than that of the krill that do not shrink (Fig. 8a). The eye diameter, however, was not greatly different between shrunk krill and nonshrunk ones even after 5 yr (Fig. 8b). When krill shrink in body length but conserve the size of their eyes, the relationship between the body length and the eye diameter becomes altered. Each time krill shrink, the body length to eye diameter relationship diverges from the one that would have been the case if the krill had not shrunk (Fig. 8c). Fig. 8d presents a magnified view of the yr between the 1st summer and the 2nd summer since hatching, which depicts how shrunk krill have developed large eyes for a given body length. The output from this simplified model agrees with what was observed in the current experiment (Figs. $3 \& 4$ ).

The change in this relationship can also be shown in the ratio of body length to eye diameter (hereafter BL/ED ratio), which is the index suggested by Sun
(1997). The BL/ED ratio will drop each time krill shrink (Fig. 9). The difference in this ratio between the shrunk krill and non-shrunk ones will be conserved even if the krill re-commence growth in body length, and it will also become greater each year if shrinkage occurs every winter. If the eye growth of krill is suspended not only for the period of body shrinkage but until the reattainment of the pre-shrinkage body length, this altered relationship will eventually return to the original one, with the recovery of body length (Fig. 9). This restoration can also be envisaged in Fig. 8c; the altered relationship caused by starvation would be fused back into the initial 'no-shrinkage' regression line (Fig. 8c). If the altered eye to body size relationship induced by shrinkage becomes lost with re-growth of the krill, then relative eye size is not a better measure of age than the body length except for the winter season and for some period in spring. By high summer, there would be no detectable difference between eye diameter and body length as an indicator of age for demographic studies. 


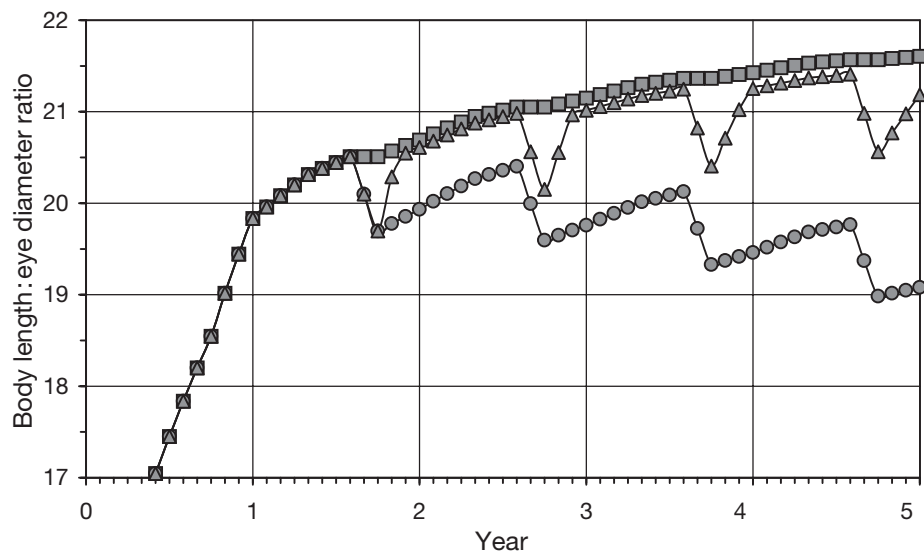

Fig. 9. Change in the ratio of body length to eye diameter over 5 yr as modeled in Fig. 8. ( $\square$ ) represent the krill that do not shrink. (0) represent the shrinking krill whose eye growth re-commences

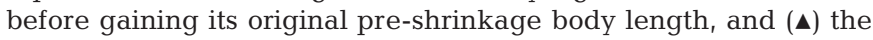
shrinking krill whose eye growth recommences only after regaining its original pre-shrinkage body length

Given the finding that eye growth is reactivated almost simultaneously with re-growth of krill, this may provide an alternative explanation for Sun's (1997) description of an exponential relationship between body length and eye diameter. As krill grow older, they may experience more years of food shortage and hence shrinkage. Consequently, a variety of altered eye size to body length relationships may be generated in the population with time. That is, as krill grow longer, more regression lines of body length and eye diameter will develop on top of the initial 'no-shrinkage' regression line (Fig. 10). Should these multiple lines fuse together, an apparent exponential relationship would appear. This illustrates the fact that eye growth is decoupled

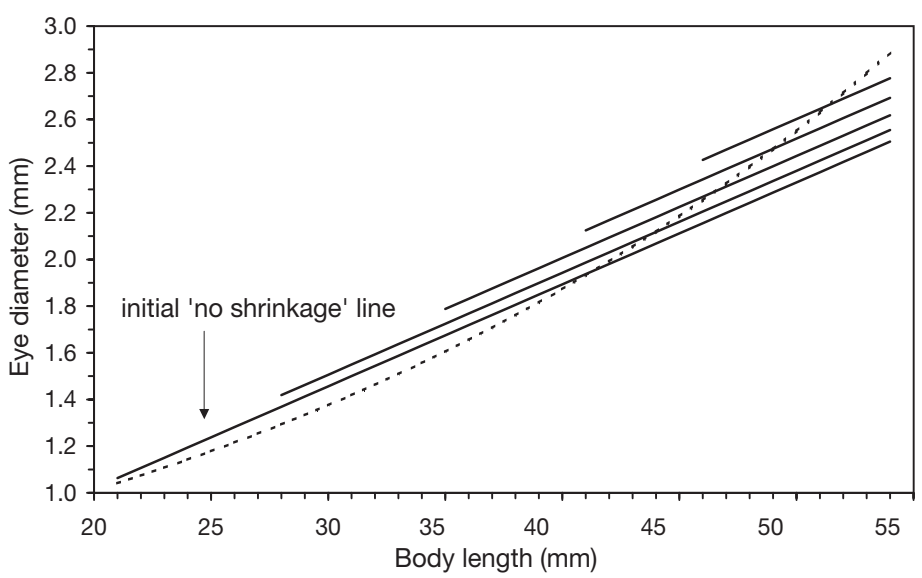

Fig.10. Multiple regression lines of body length versus eye diameter generated by shrinkage on top of the initial 'no shrinkage' line. Broken line represents the exponential relationship between the body length and eye diameter as suggested by Sun (1997) from body shrinkage while its re-activation proceeds with the recovery of body length growth. The eye size, therefore, is more conservative as a measure of age than the body length.

It appears that, should starvation proceed for more than 2 moult cycles at modest rates, a detectable change is likely to be induced in the body length to eye diameter relationship. Shrinkage by $2 \%$ moult $^{-1}$ as used in the model is not an extreme or unlikely phenomenon. Quetin \& Ross (1991) reported negative growth of -0.16 to $-2.03 \%$ moult $^{-1}$ during winter. Nicol et al. (1992) conducted 'instantaneous growth rate' measurement over an extended period and the krill showed negative growth under food limitation after as little as $7 \mathrm{~d}$. The growth rates of krill were around $-2 \%$ moult $^{-1}$ in approximately $10 \mathrm{~d}$. Buchholz (1991) also reported similar rates of shrinkage in food-deprived krill. In the starvation experiments of Ikeda \& Dixon (1982) and Virtue et al. (1997), krill continued to shrink for a number of months at a rate of 2 to $3 \%$ moult $^{-1}$. Nevertheless, how clearly these changes become manifested depends on a number of factors. The more severe the shrinkage is, i.e. the higher the shrinking rate of krill is and the more krill moult while shrinking, the more evident this alteration will be. Separate groups of different body length to eye diameter relationships will also appear in mixtures. The timing of spawning, the hatching date and the time needed to complete larval stages will vary individually, regionally and interannually, as will the growth rates of krill. All these factors contribute to an age group in a range of body size, overlapping with the next age group. How well these mixtures can be separated depends on how strongly they overlap, and this can be assessed from the examination of the body length to eye diameter relationship from field-collected specimens. However, this should not be a simple extraction of the BL/ED ratio, which is unlike other morphometric indices such as a gonado-somatic index or hepato-somatic index. These indices can indicate what stage an individual has reached in certain biological aspects. The BL/ED ratio is a population measure, not an index of individual condition.

Our simple model suggests that the altered body length to eye diameter relationship caused by shrinkage should persist and thus the effect of shrinkage should be detectable even in summer. However, by high summer, krill would have benefited from improved food supply and would have already experienced some growth. Any imprints left by winter shrinkage would probably be blurred, and the distinction between 
shrunk and non-shrunk krill becomes unclear as the krill start active growth. For the eye diameter to body length relationship to leave a detectable signal in summer, krill not only have to shrink, but more importantly, a substantial portion of the shrunk krill need to survive and then be strongly represented in the population. For these reasons, the effect of starvation and shrinkage would still be best seen at the end of winter, after the most likely period of extended food limitation. Concurrent examination of body size and eye diameter, and comparison between summer and winter will provide clues as to whether food shortage has occurred over winter.

Larval krill are much less tolerant to starvation than older krill and will die rather than shrink (Ross \& Quetin 1989). The larval krill which survive until their 1st summer would be the ones that have had access to reasonable food sources. By the time larval krill reach their 1st summer after hatching, juveniles entering their 2nd summer would probably have already grown out of winter shrinkage. Hence, there would be significant differences in most cases in the body length between age group $1+$ and $2+$. It may not be necessary to resort to the eye diameter measurements in order to separate new recruits from 2+ aged krill and older, although this may well provide clearer demarcation (Sun 1997). Nevertheless, this method may prove useful in the separation between $2+$ krill and older ones. A comparison of population structures both in eye diameter and body length, between high summer and the end of winter, will be necessary to determine the strengths and limitations of this method.

From an evolutionary perspective, krill would not have developed such a high tolerance to starvation if they did not have to deal with severe food shortage and if their life history were not food-limited. Food limitation and body shrinkage are not exclusive to Antarctic krill. Other euphausiid species have been shown to be capable of shrinkage in the laboratory and in the wild (see references in Nicol 2000). It may be that high tolerance to starvation and an ability to shrink are general features of most euphausiid species. In the case of Antarctic krill, sustained starvation and continued shrinkage do not seem to irreversibly affect the subsequent growth of krill (Thomas \& Ikeda 1987). Even though lipid reserves of krill can certainly help to buffer highly pulsed primary production in Antarctic waters, its relative importance has been calculated to be insufficient (Quetin \& Ross 1991). Additionally, its contribution has not been adequately quantified, although a more recent study indicates more extensive usage of lipid reserves than has previously been proposed (Hagen et al. 1996). It has also become known that krill can and do utilize a variety of food sources whenever they become available. Nonetheless, the extent of contribution from alternative food sources during winter remains largely unknown. The combinations of these strategies used by krill to endure until the onset of phytoplankton production in late spring, and the success or failure of krill in different winters, are still a subject for further investigations. Starvation may be an actual, recurring but unpredictable obstacle, which occurs in some years and areas, and to some populations. How frequently and systematically shrinkage occurs in natural populations and whether it occurs to such a degree that it disrupts the length frequency distribution, are yet to be shown from field studies.

If krill starve for a prolonged time in the wild, and hence shrink, the eye diameter to body length relationship should be able to indicate this, at least at the end of winter. How often krill are forced to starve and have to invoke the shrinkage strategy, could be investigated by examining specimens using this method. If a population contains juvenile krill and similarly sized krill regressed from adults, the 2 groups should be discernible by the eye diameter to body length relationship. This technique gives us a new tool to collect information that could contribute to resolving the controversy of shrinkage and to advancing knowledge of the overwintering biology and recruitment of krill.

Acknowledgements. Special thanks go to Robert King and Paul Cramp at the Australian Antarctic Division, whose assistance was absolutely critical in keeping krill alive and finishing the experiment. Comments from Robin Ross, Andrew McMinn and anonymous reviewers are appreciated. The first author's enrollment at the University of Tasmania was supported by an Overseas Postgraduate Research Scholarship from the Australian Government and he gratefully acknowledges the partial stipend scholarship from the Australian Antarctic Division.

\section{LITERATURE CITED}

Buchholz F (1991) Moult cycle and growth of Antarctic krill Euphausia superba in the laboratory. Mar Ecol Prog Ser 69:217-229

Dalpadado P, Ikeda T (1989) Some observations on moulting, growth and maturation of krill (Thysanoessa inermis) from the Barents Sea. J Plankton Res 11:133-139

Ettershank G (1984) A new approach to the assessment of longevity in Antarctic krill, Euphausia superba. J Crustac Biol 4(Spec Issue 1):295-305

Everson I, Goss C (1991) Krill fishing activity in the southwest Atlantic. Antarct Sci 3:351-358

Gutt J, Siegel V (1994) Benthopelagic aggregations of krill (Euphausia superba) on the deeper shelf of the Weddell Sea (Antarctic). Deep-Sea Res I 41:169-178

Hagen W, Van Vleet ES, Kattner G (1996) Seasonal lipid storage as overwintering strategy of Antarctic krill. Mar Ecol Prog Ser 134:85-89

Hosie GW, Ritz DA (1989) Body shrinkage in the sub-tropical euphausiid Nyctiphanes australis G.O. Sars. J Plankton Res 11:595-598

Huntley ME, Nordhausen W, Lopez MDG (1994) Elemental 
composition, metabolic activity and growth of Antarctic krill Euphausia superba during winter. Mar Ecol Prog Ser 107:23-40

Ikeda T, Dixon P (1982) Body shrinkage as a possible overwintering mechanism of the Antarctic krill, Euphausia superba Dana. J Exp Mar Biol Ecol 62:143-151

Ikeda T, Thomas PG (1987) Moulting interval and growth of juvenile Antarctic krill (Euphausia superba) fed different concentrations of the diatom Phaeodactylum tricornutum in the laboratory. Polar Biol 7:339-343

Loeb V, Siegel V, Holm-Hansen O, Hewitt R, Fraser W, Trivelpiece W, Trivelpiece S (1997) Effects of sea ice extent and krill or salp dominance on the Antarctic food web. Nature 387:897-900

Marinovic B, Mangel M (1999) Krill can shrink as an ecological adaptation to temporarily unfavourable environments. Ecol Lett 2:338-343

McClatchie S (1988) Food-limited growth of Euphausia superba in Admiralty Bay, South Shetland Islands, Antarctica. Cont Shelf Res 8:329-345

McClatchie S, Rakusa-Suszczewski S, Filcek K (1991) Seasonal growth and mortality of Euphausia superba in Admiralty Bay, South Shetland Islands, Antarctica. ICES J Mar Sci 48:335-342

Nicol S (2000) Understanding krill growth and aging: the contribution of experimental studies. Can J Fish Aquat Sci 57(Suppl 3):168-177

Nicol S, Stolp M, Hosie GW (1991) Accumulation of fluorescent age pigments in a laboratory population of Antarctic krill (Euphausia superba Dana). J Exp Mar Biol Ecol 146: 153-161

Nicol S, Stolp M, Cochran T, Geijsel P, Marshall J (1992) Growth and shrinkage of Antarctic krill Euphausia superba from the Indian Ocean sector of the Southern Ocean during summer. Mar Ecol Prog Ser 89:175-181

Nicol S, Kitchener J, King R, Hosie GW, de la Mare WK (2000) Population structure and condition of Antarctic krill (Euphausia superba) in CCAMLR Division 58.4.1 $\left(80-150^{\circ} \mathrm{E}\right)$ during January-March 1996. Deep-Sea Res II 47:2489-2517

Quetin LB, Ross RM (1991) Behavioral and physiological char-

Editorial responsibility: Otto Kinne (Editor),

Oldendorf/Luhe, Germany acteristics of the Antarctic krill, Euphausia superba. Am Zool 31:49-63

Ross RM, Quetin LB (1989) Energetic cost to develop to the first feeding stage of Euphausia superba Dana and the effect of delays in food availability. J Exp Mar Biol Ecol 133:103-127

Siegel V (1989) Winter and spring distribution and status of the krill stock in Antarctic Peninsula waters. Arch Fischwiss 39:45-72

Siegel V, Loeb V (1995) Recruitment of Antarctic krill Euphausia superba and possible causes for its variability. Mar Ecol Prog Ser 123:45-56

Smetacek V, Scharek R, Nothig EM (1990) Seasonal and regional variation in the pelagial and its relationship to the life history cycle of krill. In: Kerry KR, Hempel G (eds) Antarctic ecosystems: ecological change and conservation. Springer-Verlag, Berlin, p 103-114

Stepnik R (1982) All-year populational studies on the Euphausiacea (Crustacea) in the Admiralty Bay (King George Island, South Shetland Islands, Antarctic). Pol Polar Res 3: $49-68$

Stretch JJ, Hamner PP, Hamner WM, Michel WC, Cook J, Sullivan CW (1988) Foraging behaviour of Antarctic krill Euphausia superba on sea ice microalgae. Mar Ecol Prog Ser 44:131-139

Sun S (1997) Using Antarctic krill as an indicator of environmental interannual change. Korean J Polar Res 8:97-103

Sun S, de la Mare W, Nicol S (1995) The compound eye as an indicator of age and shrinkage in Antarctic krill. Antarct Sci 7:387-392

Thomas PG, Ikeda T (1987) Sexual regression, shrinkage, rematuration and growth of spent female Euphausia superba in the laboratory. Mar Biol 95:357-363

Virtue P, Nichols PD, Nicol S (1997) Dietary-related mechanisms of survivial in Euphausia superba: biochemical changes during long-term starvation and bacteria as a possible source of nutrition. In: Battaglia B, Valencia J, Walton DWH (eds) Antarctic communities. Cambridge University Press, Cambridge, p 193-201

Zar JH (1996) Biostatistical analysis. Prentice-Hall, Upper Saddle River, NJ

Submitted: December 1, 2000; Accepted: February 5, 2001

Proofs received from author(s): August 6, 2002 